\title{
Effect of Object Location on Selecting the Limb in Unilateral Reaching in 5- to 6-Year-Old Children
}

Mohsen Sarhady ${ }^{1}$, Seyed Mohammad Sadegh Hosseini' ${ }^{1}$, Sahar Nourani Gharaborgha ${ }^{*}$

1. Department of Occupational Therapy, School of Rehabilitation, Hamedan University of Medical Sciences, Hamedan, Iran.

Citation: Sarhady M, Sadegh Hosseini SM, Nourani Bargha S. Effect of Object Location on Selecting the Limb in Unilateral Reaching in 5- to 6-Year-Old Children. Physical Treatments. 2016; 5(4):197-204.

do):

Article info:

Received: 14 Jul. 2015

Accepted: 28 Nov. 2015
Keywords:

Dominant hand, Handedness, Reaching, Children, Limb selection, Object location

\begin{abstract}
A B S T RA C T
Purpose: The traditional view regards limb selection in reaching a hemispheric specialization and an permanent biological phenomenon. However, recent studies have questioned this idea Instead, they suggest that the task conditions is also an effective factor. The present study includes two experiments in right and left handed children examining the effect of object location as a task condition on limb selection in unilateral reaching.
\end{abstract}

Methods: A total of 84 children aged 5-6 years (48 right handed and 36 left handed) were recruited in this study. Participants performed reaching task in two conditions: 1) Picking a cube from 1 of 7 locations and putting it in a box placed in the front of them at mid-line and 2) Picking a cube from 1 of 7 locations and putting it in a box placed on the opposite location.

Results: Measurement was performed by calculating and recording the percentages of the responses and the data were analyzed using Chi-square test. In both experiments, most of the subjects used their dominant limb in the ipsilateral hemispace $(\mathrm{P}<0.05)$. It was more consistent in right handed children. In the second experiment, the left dominant children used their left upper limb more frequently in the ipsilateral hemispace but the right handed children used their right upper limb in almost all situations.

Conclusion: The findings of this study are against the end-state comfort and in accordance with the hemispheric bias hypothesis. The findings are in line with previous studies that the object location can affect limb selection in unilateral reaching in children.

\section{Introduction}

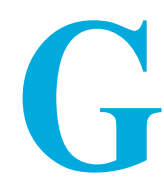

eneral and common view regarding the hand selection for performing one-handed tasks is that, during development and under the influence of brain lateralization, one hand is selected as the dominant one, and is used for all performances, even if activities are done in a difficult or inconvenient manner [1]. However in recent years, research studies have strongly challenged this view. Several studies [2-7] have shown that, in different aspects of functional behaviors, left-handed people, compared to right-handed ones, show more variation and less lateralization (despite being the dominant side). For

\section{* Corresponding Author:}

Sahar Nourani Gharaborgha, MSc.

Address: Department of Occupational Therapy, School of Rehabilitation, Hamedan University of Medical Sciences, Hamedan, Iran.

Phone: +98 (81) 38381571

E-mail: saharnurani@yahoo.com 
the right-hand, also, the previous studies could not clearly show its consistent use in functional activities. Although "reaching" has been extensively studied in children, most studies have focused on the development of movement control [8-10], rather than on planning for selecting the limp for this movement. Apparently, the reason for giving up these studies was the general belief that handedness is a fixed developmental process that cannot be altered [11].

More recent studies tend to accept the idea that handedness is not necessarily a constant and unchanging biological phenomenon, and that limb selection may be influenced by attentional stimuli from special requirements of the task being performed and the environmental context [12-15]. According to these facts, motor planning for upper limb selection to do the reaching, seems to be affected by two factors: handedness and attentional stimuli from special requirements of the task $[11,12,16]$. In the study in which these two factors were extracted, participants were asked to reach their hands to grasp a small cube in 9 different locations upon hearing an auditory stimulus. This study indicated a specific and constant behavioral pattern. In summary, while all participants used their dominant hands at middle positions and in the space ipsilateral to their dominant hands $(99 \%)$, both right-handed and left-handed groups showed a completely different pattern in the spatial region in the space contralateral to their dominant hands (ipsilateral to their non-dominant hand), so that the use of dominant hand in the non-dominant spatial region (the opposite space) had a significant decrease (about 30\%), i.e. about $70 \%$ of the participants preferred to use their non-dominant hand for a stimulus presented in the non-dominant region. In other words, hand preference changed according to attentional stimuli related to special requirements of the task.

Attentional information from object location creates changes in motor planning through influencing the motor dominance factor in action planning in the spatial region in the space contralateral to the limb. Therefore, people simply use the most appropriate and comfortable response based on the spatial relationship between the limb and the object [17-19]. When an object is to be picked up and taken to another place, the task is finished once the upper limb is in a final, comfortable position (a position in which joints are close to it, in their range of motion or as much as possible) [20]. Rosenbaum et al. [21-23] have clearly shown the preference of the middle range for finishing the movement. They found that when a cylinder needs to be reached by hand, grasped, moved to another place, and put upside-down, people usually supinate their hands from the beginning and perform the activity in a difficult and unpleasant manner (keeping the inner edge of the hand downward). Then, once the object is finally put in the intended place, by turning the cylinder, the hand will be in a comfortable position. This phenomenon is called "end-state comfort" and has been observed in numerous tasks, including moving a pole or rotating a handle [21, $22,24-26]$.

The goal of the present study was to examine the effect of object location (in two spatial hemispheres each at the side of the dominant and non-dominant hands) on limb selection for reaching (in preschool children aged 5-6 years old). The second goal of the study was to determine whether the "endstate comfort" has any impact on limb selection for hand reaching toward the space contralateral to the grasping limb, and moving the object to the ipsilateral space. The Gabbard et al. paradigm is used in the present study [11,27].

\section{Materials and Methods}

The study sample included a total of 84 children (53 girls and 31 boys) aged 5-6 years, who were selected from kindergartens and preschools in west area of Tehran. The mean age of participants was 72.5 months $(\mathrm{SD}=10.4)$. Forty-eight children were right-handed and 36 were left-headed. Among lefthanded participants, 28 were girls and 8 were boys; among right-handed participants, 25 were girls and 23 were boys. The handedness was determined using reports provided by mothers and kindergarten teachers. Kindergarten teachers determined the handedness from children's preferred hands for writing, and using eraser and colored pencils [11]. Mothers determined the handedness from their children's preferred hand for holding spoon and brushing. Children, who according to the reports from both mothers and teachers, used their right or left hands to perform these activities were considered as right-handed or left-handed (Figure 1).

In order to perform the test, a large, white paperboard adhered to a table top was used. A line had been drawn on the middle of the paperboard, and lines showing 10, 30, 50, and 70 degrees had been drawn on both sides. Participants sat behind this table and put their hands on their legs in a relaxing manner. The instruments used included a small wooden cube $(2.5 \mathrm{~cm})$ and a paperboard box. The study task included reaching and grasping. There is minimum involvement of cognitive ability in this simple activity [11].

After determining the dominant limb using the method mentioned above, written permissions were obtained from mothers, and if they wanted, they could be present where the task was performed. Before starting the activity, a simple and brief explanation was given to the child about the goals and methods of the study. The task was performed in two stages: in the first stage, the child sat on the chair, behind the table, and against the middle line. The box was 
also put on the middle line and $15 \mathrm{~cm}$ away from the child's body. Children were asked to close their eyes and not open them until hearing the word "now", and after hearing that, pick up the cube, and put it inside the box. These stages were done in all 7 determined points. The order of performing the task was as follows: first in the middle line, then to the right side, and finally to the left side.

In the second stage, participants sat in a position similar to the first stage. They were asked to, upon hearing the word "now" (like the first stage), reach their hands toward the wooden cube in a spatial region, grasp it, and put it on the corresponding location in the other spatial region. Therefore, the stages were as follows:

- Cube in 30 degrees right, box in 30 degrees left (R30-L30)

- Cube in 50 degrees right, box in 50 degrees left (R50-L50)

- Cube in 70 degrees right, box in 70 degrees left (R70-L70)

- Cube in 70 degrees left, box in 70 degrees right (R70-L70)

- Cube in 50 degrees left, box in 50 degrees right (R50-L50)

- Cube in 30 degrees left, box in 30 degrees right (R30-L30)

\section{Results}

Stage one

The results from the stage one are presented in Table 1 and Figure 2. As the profile of mixed responses of the two groups indicates, in general, both groups used their dominant limbs in the ipsilateral space, from the contralateral space. The average responses for two groups in the ipsilateral and con- tralateral spaces were $92.2 \%$ and $46.4 \%$, respectively. This means that when the cube is in the space contralateral to the dominant limb, $53.5 \%$ of responses are performed by using the non-dominant hand. According to the Chi-square test results, the difference between dominant hand responses in the ipsilateral space and non-dominant hand responses in the contralateral space was statistically significant $(\mathrm{P}<0.05)$. Significant differences were also found with regard to the use of dominant hand in the ipsilateral and contralateral spaces at all positions. To put it simply, when the cube was in the right side of the right-handed participants, they tended to use their right hand, and when it was in the left side, they tended to use their non-dominant hands, i.e. their left hands (e.g. in the position 30 degrees right and 30 degrees left).

The Chi-square test indicated that the only significant differences between right- and left-handed participants was in the middle line, i.e. the difference between $93.7 \%$ and $69.4 \%$ $(\mathrm{P}<0.05)$. By considering the contralateral space, the only significant difference was found in the 50 degrees position $(\mathrm{P}<0.05)$.

Overall, these results complete the previous findings $[1,6,11-16,27]$. In one of these studies, when children reached their hands to grasp an object outside the middle area in a dark and normal condition, they commonly used their limb ipsilateral to the object. In a review of their own studies on visually guided reaching, Harris and Carlson [28], reported a constant behavioral pattern similar to what presented here. That is, when the object is outside the middle line, both children and adults tend to reach with their limbs ipsilateral to the object, regardless of whether it is the dominant limb or not.

One of their general conclusion was that object location strongly influences the limb selection. They used the principle of least effort to determine this behavior. There are two explanations for the observed behavior in reaching, i.e. selection of the limb ipsilateral to the object. One explanation was provided by the kinesthetic hypothesis and the other by the hemispheric bias [29]. The kinesthetic explanation indicates that biomechanical limitations

Table 1. Number and percentage of responses of the dominant limb for each group in the first stage.

\begin{tabular}{|c|c|c|c|c|c|c|c|}
\hline & \multicolumn{3}{|c|}{ Left Spatial Field } & \multirow{2}{*}{$\begin{array}{c}\text { Middle Line } \\
90\end{array}$} & \multicolumn{3}{|c|}{ Right Spatial Field } \\
\hline & 30 & 50 & 70 & & 70 & 50 & 30 \\
\hline Right-handed group ( $n=48$ ), & 19 & 27 & 29 & 45 & 46 & 46 & 47 \\
\hline $\begin{array}{c}\text { Number of responses, } \\
\text { Percentage of responses (\%) }\end{array}$ & 37.2 & 56.2 & 60.4 & 93.7 & 95.8 & 95.8 & 97.9 \\
\hline Left-handed group ( $n=36$ ), & 34 & 31 & 30 & 25 & 18 & 14 & 13 \\
\hline $\begin{array}{c}\text { Number of responses, } \\
\text { Percentage of responses (\%) }\end{array}$ & 94.4 & 86.1 & 83.3 & 69.4 & 50 & 38.8 & 36.1 \\
\hline
\end{tabular}




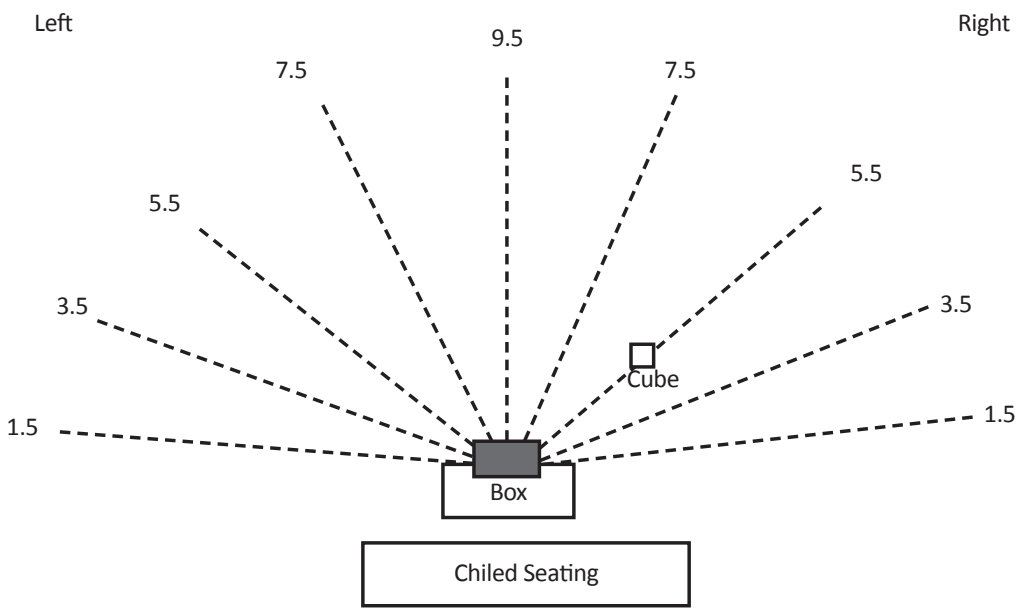

Figure 1. The setup used for examining limb use.

(degrees of freedom) imposed on the task performance cause the person to plan the most appropriate, efficient, and comfortable response according to hand joints coordinates, in a way that it is completed with the least movement and use of energy [18, 19]. For example, for a righthanded person, reaching an object on the left side with the right hand, requires much biomechanical energy and movement, passing through the middle line, and covering a longer space. However, doing that with the left hand is more convenient, despite the fact that it is non-dominant.

Mark et al. [17] added to this explanation stating that a person's selection of how to perform and reach a particular situation is, before anything else, evoked by the postural dynamics. In ipsilateral reaching, one degree of freedom of movement, i.e. arm is controlled. But in contralateral reaching (passing the middle line), because more distance is covered, the body also gets involved, and more degrees of freedom need to be controlled (in addition to arm, body is also involved). The hemispheric bias hypothesis is, in fact, what psychological studies on motion refer to as "stimulus-respond compatibility". This hypothesis is based on works of Simon and Hei- lman in the late 80 s to mid-90s [27]. It maintains that in the reaching activity, preference for using the hand ipsilateral to the stimulus involves an attentional (hemispheric) bias. According to this hypothesis, responding to a stimulus ipsilateral to the performing limb is more comfortable, and involves less attentional requirements.

In summary, the present study supports these two hypotheses regarding handedness and reaching. However, motor laterality is clearly a controlling factor in motor planning in response to a stimulus in the ipsilateral field or in the middle line. But, for objects in the contralateral field, attentional information has the most impact on limb selection. Attentional information is kinesthetic information that a person perceives.

As you can see in the response profile of the two groups (Figure 2), right-handed relative to left-handed participants, showed more stability and compatibility in using their dominant limbs. Right-handed participants also showed greater use of their dominant hands in the contralateral field. In the 30 degrees filed that involved a significant difference between right-handed and left-handed participants, also, right-handed participants used their

Table 2. Number and percentage of responses of the dominant limb for each group in the Second stage.

\begin{tabular}{|c|c|c|c|c|c|c|}
\hline \multirow{2}{*}{ Groups } & \multicolumn{3}{|c|}{ Left Spatial Region } & \multicolumn{3}{|c|}{ Right Spatial Region } \\
\hline & L30-R30 & L50-R50 & L70-R70 & R70-L70 & R50-L50 & R50-L30 \\
\hline Right-handed group $(n=48)$, & 43 & 45 & 48 & 48 & 48 & 48 \\
\hline $\begin{array}{c}\text { Number of responses, } \\
\text { Percentage of responses (\%) }\end{array}$ & 89.5 & 93.7 & 100 & 100 & 100 & 100 \\
\hline Left-handed group ( $n=36)$, & 35 & 30 & 28 & 34 & 29 & 12 \\
\hline $\begin{array}{c}\text { Number of responses, } \\
\text { Percentage of responses (\%) }\end{array}$ & 96.9 & 83.1 & 77.5 & 98.2 & 80.3 & 33.3 \\
\hline
\end{tabular}




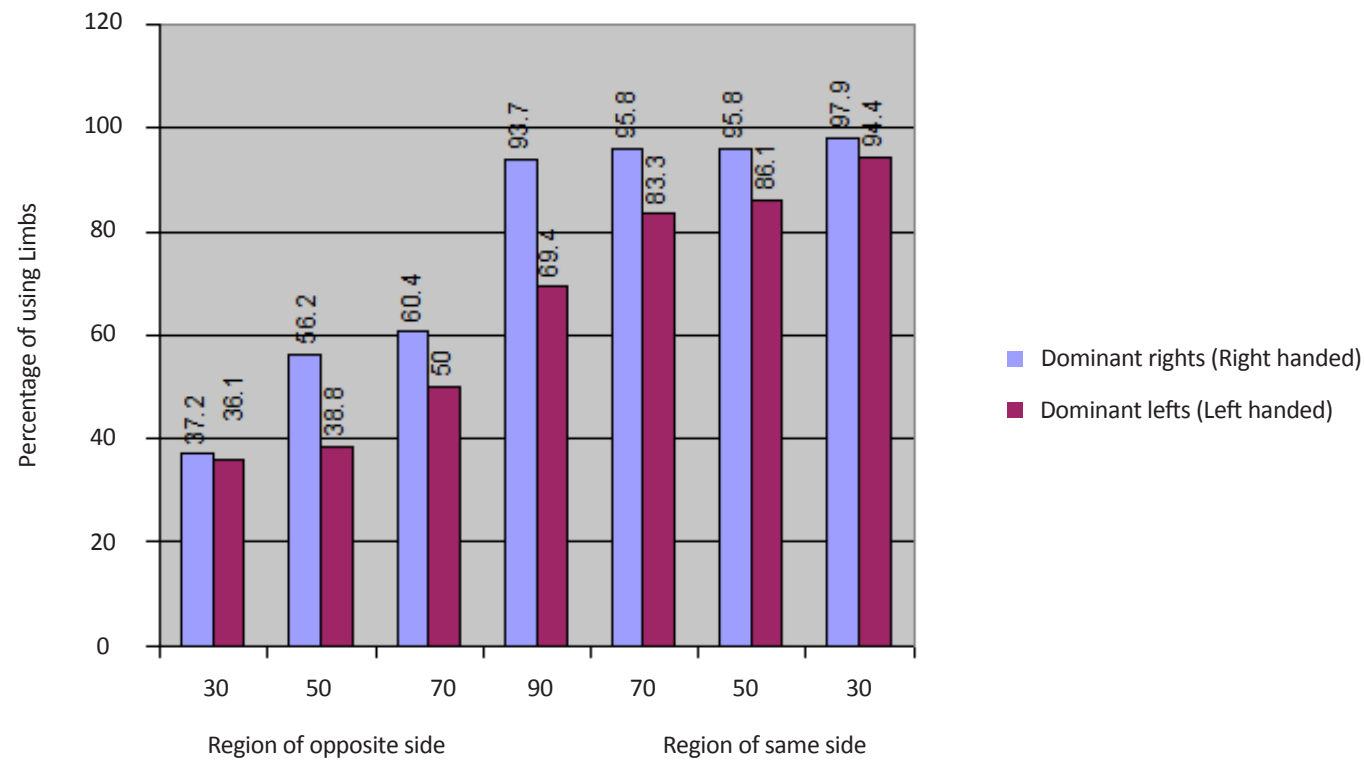

PHYSICAL TREA T MENTS

Figure 2. Dominant limb use in homo and lateral hemispace for the right and left dominant group (first stage).

dominant limbs more than left-handed participants $(56.2 \%$ vs $38.8 \%)$.

Interpretation of findings from an attentional perspective indicates that left-handed people compared to righthanded ones, plan their movements in a different way. They are more dependent on attentional information for reaching in the contralateral field. It can also be argued that the stability in the use of dominant limb observed in right-handed people, rather than brain differences, is due to the experience of living in a world that prefers righthandedness. For example, according to the "right-handed world" theory [30], left-handed people see the world as a difficult place to live, and different tools and facilities in the world are designed for right-handed people.

\section{Stage two}

The main question in this stage is that whether the subjects would show the same pattern observed in the first stage, if

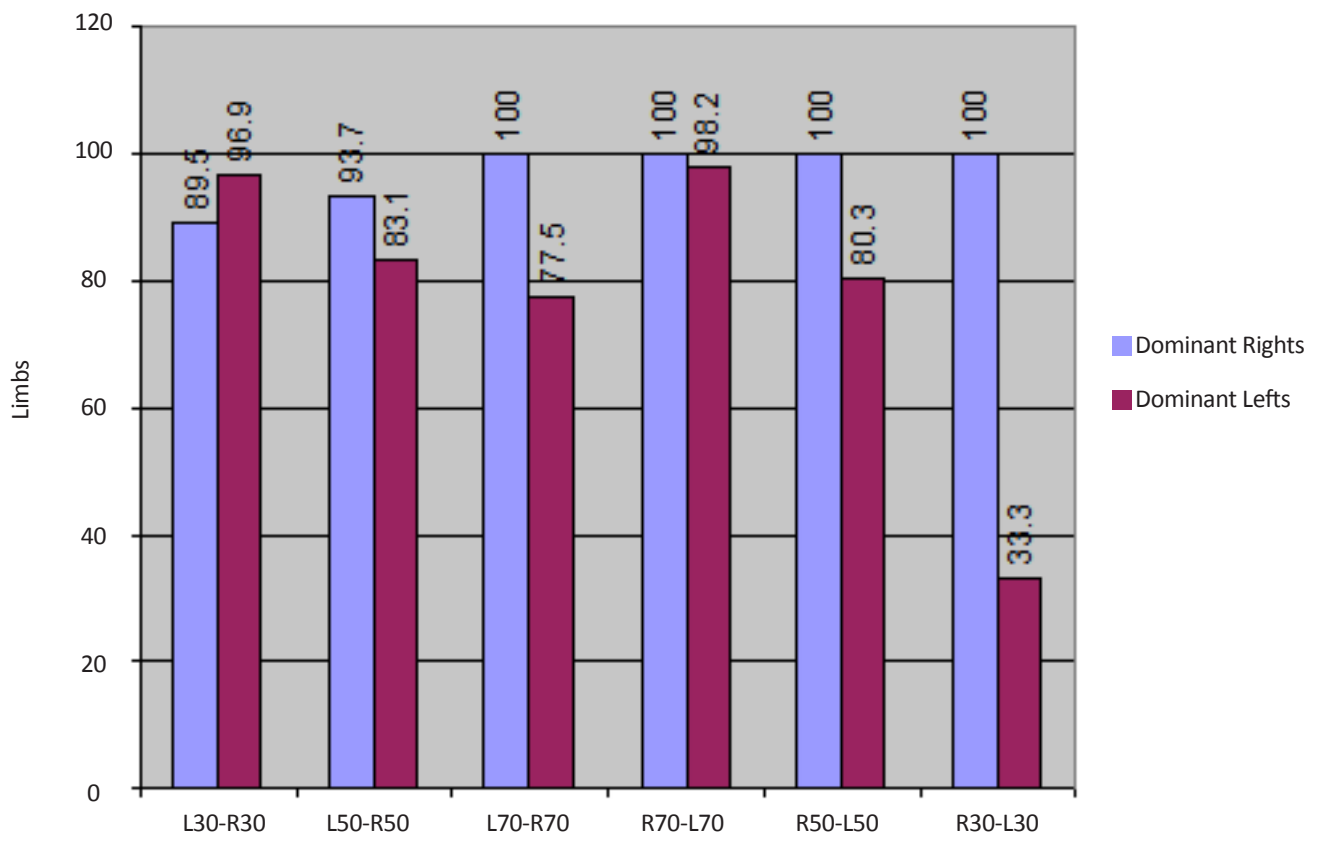

PHYSICAL TREA $\pitchfork$ MENTS

Figure 3. Dominant limb use in different angles for the right and left dominant group (second stage) 
the task performed in two stages got more difficult. Table 2 shows the number and percentage of responses for both right-handed and left-handed groups, and Figure 3 shows the response profile. As mentioned earlier, participants were asked to pick up an object from a specific position on one side and put it on a corresponding position on the other side. As you can see in the response profile (Figure 3 ), when the object is in the ipsilateral field and needs to be transferred to the opposite side, and vice versa, righthanded people show a similar behavior, and the Chisquare test reveals no significant difference $(\mathrm{P}>0.05)$. On average, at 6 positions, right-handed participants showed $97.2 \%$ use of dominant limb. In the L70-R70 positions toward right, i.e. the ipsilateral field, right-handed participants showed $100 \%$ use of dominant hand.

Left-handed people show a somewhat different pattern that is incompatible or less stable; from the end of the left side, i.e. where the cube is at L30-R30, toward the nearest position to the middle line, i.e. L70-R70, the use of dominant hand gradually decreases. This decrease is also observed in the contralateral field. However, at R70-L70, like the corresponding position, the use of dominant hand by left-handed participants increases, and reaches to the minimum point at R30-L30. For left-handed participants, the average responses in the ipsilateral and contralateral fields are $85.8 \%$ and $70.6 \%$, respectively; according to the Chi-square test, this difference is significant $(\mathrm{P}<0.01)$. That is, in left-handed participants, the use of dominant hand in the ipsilateral field is significantly higher than that in the contralateral field. In general, according to the results of the Chi-square test, the use of dominant limb was different between right-handed and left-handed participants $(\mathrm{P}<0.01)$; it was $97.2 \%$ and $78.2 \%$ for righthanded and left-handed participants, respectively.

Among the 6 positions, there was a significant difference between the two groups at R50-L50 positions ( $\mathrm{P}<0.01$ for each position). However, no significant difference was found at other positions. Nevertheless, at all positions except the leftmost one, the use of dominant limb was higher in right-handed compared to left-handed participants. The highest difference between the two groups was at the R30-L30 position that was $100 \%$ for right-handed and $33.3 \%$ (about one third) for left-handed participants.

As it was said earlier, the "end-state comfort" theory [20, 23], maintains that people start a movement in a way that when it is finished, the performing limb would be in the most comfortable position, i.e. a position that involves the least distance and use of energy, and relative to the limb's coordinates, involves the least movements. The study findings do not support this hypothesis, and our results refute that. As we expected, when the cube is in the space ipsilateral to the dominant limp and the box in the contralateral space, the correct choice is using the non-dominant limb, because in such condition, the end state is closer to the non-dominant limb. However, right-handed people use their right hands to grasp an object, regardless of where the object is located (i.e. in the ipsilateral or contralateral space) (average response $=97.2 \%$ ). For left-handed people also this hypothesis not only did not gain support, but also was rejected. Because left-handed people show greater use of their left limbs when the cube is on the left side and should be put on the right side compared to when the cube is on the right side and should be put on the left side ( $85.8 \%$ vs $70.6 \%)$.

This finding is contrary to the "end-state comfort" theory. The study results are more consistent with the "hemispheric bias" hypothesis. What we observed in the present study was that limb selection is based on object location rather than where the movement will end. Some of these findings are in line with the findings of Gabbard et al. [27]. They only worked with right-handed participants, and observed a gradual decrease in the use of limb in the ipsilateral space and a gradual increase of its use in the contralateral space; this is consistent with our findings.

\section{Discussion}

The two stages of the present study revealed that, regardless of task complexity, object location as a stimulus is one of the determining factors in limb selection. It is observable that in right-handed people, in addition to object location, laterality is also an effective factor. That is, in right-handed people compared to left-handed ones, limb dominance is more influenced by attentional information from special parameters of a task. The important implication of these findings for developmental studies and interventions is that laterality is not only affected by biological factors, but also influenced by task properties. In interventions also, by organizing the task environment and properties, it is possible to guide a person toward greater use of a target limb, in order to facilitate the use of an intended limb.

\section{Acknowledgements}

The authors whould the research comitee of Hamadan University of Medical Sciences for ethical approval of the project. They also would like to thank the children, parents and administratores of the kindergartens and preschools for participating in the research.

\section{Conflict of Interest}

The authors declared no conflict of interests. 


\section{Reference}

[1] Bryden MP, Singh M, Steenhuis RE, Clarkson KL. A behavioral measure of hand preference as opposed to hand skill. Neuropsychologia. 1994; 32(8):991-99. doi: 10.1016/00283932(94)90048-5

[2] Brysbaert M. Lateral preferences and visual field asymmetries: Appearances may have been overstated. Cortex. 1994; 30(3):413-29. doi: 10.1016/s0010-9452(13)80338-3

[3] Hellige JB, Bloch MI, Cowin EL, Lee Eng T, Eviatar Z, Sergent $\mathrm{V}$. Individual variation in hemispheric asymmetry: multitask study of effects related to handedness and sex. Journal of Experimental Psychology. 1994; 123(3):235-56. doi: 10.1037/0096-3445.123.3.235

[4] Curt F, Maccario J, Dellatolas G. Distributions of hand preference and hand skill asymmetry in preschool children: Theoretical implications. Neuropsychologia. 1992; 30(1):2734. doi: 10.1016/0028-3932(92)90011-a

[5] De Gostini M, Pareé C, Goudot D, Dellatolas G. Manual preference and skill development in preschool children. Developmental Neuropsychology. 1992; 8(1):41-57. doi: $10.1080 / 87565649209540514$

[6] Gabbard C, Hart S, Gentry V. General motor proficiency and handedness in children. Journal of Genetic Psychology. 1995; 156(4):411-16. doi: 10.1080/00221325.1995.9914833

[7] Laeng B, Peters M. Cerebral lateralization for the processing of spatial coordinates and categories in left-and right-handers. Neuropsychologia. 1995; 33(4):421-39. doi: 10.1016/00283932(94)00126-a

[8] Berthier NE. Learning to reach: A mathematical model. Developmental Psychology. 1996; 32(5):811-23. doi: 10.1037//0012-1649.32.5.811

[9] Konczak J, Borutta M, Dichgans J. The development of goaldirected reaching in infants II. Learning to produce task-adequate patterns of joint torque. Experimental Brain Research. 1997; 113(3):465-74. doi: 10.1007/ pl00005599

[10] Thelen E, Corbetta D, Spencer JP. Development of reaching during the first year: role of movement speed. Journal of experimental psychology: human perception and performance. 1996; 22(5):1059-76. doi: 10.1037//00961523.22.5.1059

[11] Gabbard C, Helbig CR, Gentry V. Lateralized effects on reaching by children. Developmental Neuropsychology. 2001; 19(1):41-51. doi: 10.1207/s15326942dn1901_4

[12] Gabbard C, Iteya M, Rabb C. A lateralized comparison of handedness and object proximity. Canadian Journal of Experimental Psychology. 1997; 51(2):176-80. doi: 10.1037/1196-1961.51.2.176

[13] Hellige JB, Kee DW. Asymmetric manual Interference as in indicate of lateralized brain function. In: Hammond GR, editor. Cerebral Control of Speech and Limb Movement. Amsterdam: Elsevier Pub; 1990, p. 635-660.

[14] Peters M. Handedness and its relation to other indices of cerebral lateralization In: Davidson RJ, Hugdahl K, editor. Brain Asymmetry. Cambridge: MIT Press; 1995, p. 183-214.

[15] Verfaellie M, Heilman KM. Hemispheric asymmetries in attentional control: Implications for hand preference in sen- sorimotor tasks. Brain \& Cognition. 1990; 14(1):70-80. doi: 10.1016/0278-2626(90)90061-r

[16] Gabbard C, Rabb C, Gentry V. Attentional stimuli and programming hand selection: a developmental perspective. International Journal of Neuroscience. 1998; 96(3-4):205-15. doi: $10.3109 / 00207459808986468$

[17] Mark LS, Nemeth K, Gardner D, Dainoff MJ, Paasche J, Duffy M, et al. Postural dynamics and the preferred critical boundary for visually guided reaching. Journal of Experimental Psychology: Human Perception \& Performance. 1997; 23(5):1365-79.

[18] Rosenbaum DA. Human motor control. San Diego: Academic Press; 1991.

[19] Stins JF, Michaels CF. Stimulus-target compatibility for reaching movements. Journal of Experimental Psychology: Human Perception and Performance. 1997; 23(3):756-767. doi: 10.1037//0096-1523.23.3.756

[20] Steenbergen B, Meulenbroek RG, Rosenbaum DA. Constraints on grip selection in hemiparetic cerebral palsy: effects of lesional side, end-point accuracy, and context. Cognitive Brain Research. 2004; 19(2):145-59. doi: 10.1016/j. cogbrainres.2003.11.008

[21] Rosenbaum DA, Marchak F, Barnes HJ. Constraints for action selection overhand versus underhand grasps. In: Jeannerod M, editor. Attention and Performance XIII. New Jersey: Lawrence Erlbaum Publishers; 1995, p.321-342.

[22] Rosenbaum DA, Vaughan J, Barnes HJ, Jorgensen MJ. Time course of movement planning: Selection of handgrips for object manipulation. Journal of Experimental Psychology: Learning, Memory, \& Cognition. 1992; 18(5):1058-073. doi $10.1037 / / 0278-7393.18 .5 .1058$

[23] Rosenbaum DA, van Heugten CM, Caldwell GE. From cognition to biomechanics and back: The end-state comfort effect and the middle-is-faster effect. Acta Psychologica. 1996; 94(1):59-85. doi: 10.1016/0001-6918(95)00062-3

[24] Fischman MG. Constraints on grip-selection: minimizing awkwardness. Perceptual and Motor Skills. 1998; 86(1):32830. doi: $10.1177 / 003151259808600102$

[25] Rosenbaum DA, Jorgensen MJ. Planning macroscopic aspects of manual control. Human Movement Science. 1992; 11(1-2):61-69. doi: 10.1016/0167-9457(92)90050-1

[26] Rosenbaum DA, Vaughan CM, Jorgensen MJ. Plans for objects manipulation. In: Meger DE, Kornblum S, editors. Attention and Perfomance XIV: Synergies in Experimental Psychology, Artificial Intelligence, and Cognitive Neuroscience. Massachusetts: MIT Press; 1993, p. 803-20.

[27] Gabbard C, Tapia M, Helbig CR. Task complexity and limb selection in reaching. International Journal of Neuroscience. 2003; 113(2):143-52. doi: 10.1080/00207450390161994

[28] Harris KJ, Carlson DF. Hand preference for visuallyguided reaching in human infants and adults. In: Ward JP Hopkins WD, editors. Human Laterality: Current Behavioral Evidence of Primate Asymmetries. New York: Springer; 1993, p. 285-93.

[29] Gabbard C, Rabb C. What determines choice of limb for unimanual reaching movements? Journal of general psychology. 2000; 127(2):178-84. doi: 10.1080/00221300009598577 
[30] Porac C. Are age trends in adult hand preference best explained by developmental shifts or generational differences?. Canadian Journal of Experimental Psychology. 1993; 47(4):697-713. doi: 10.1037/h0078873 